\title{
Conventional Ventilation Lung Protective Strategies
}

Rob Graham, R.R.T./N.R.C.P.

I dedicate this column to the late Dr. Andrew (Andy) Shennan, the founder of the perinatal program at Women's College Hospital (now at Sunnybrook Health Sciences Centre). To my teacher, my mentor and the man I owe my career as it is to, thank you. You have earned your place where there are no hospitals and no NICUs, where all the babies do is laugh and giggle and sleep.

"Regular readers of this column will be aware of my preference for highfrequency ventilation (HFV) for lung protection. Indeed, I have not routinely used conventional ventilation (CV) for over 15 years."

Regular readers of this column will be aware of my preference for high-frequency ventilation (HFV) for lung protection. Indeed, I have not routinely used conventional ventilation (CV) for over 15 years. That being said, I realize there are many units that either do not have access to HFV or only use these modes as "rescue therapy."

Years before HFV was available to me as a clinician, CV was the only option for my patients. Initially, only basic IMV ventilators were available, and it was not until the 1990s that patient synchronized modes were introduced. Virtually all intubated babies were started at a respiratory rate of 40-60, peak inspiratory pressure (PIP) of 20, inspiratory time (Ti) of 0.4 seconds, and PEEP of 5 . The rate was decreased before PIP; neither PEEP nor Ti was virtually ever changed. Unfortunately, one size does not fit all.

The first of these modes was synchronized intermittent mandatory ventilation (SIMV). The first attempts at synchronization used abdominal sensors and did not work very well (in fact, we had no success with them whatsoever). Only when flow sensors arrived on the scene did synchronization became reliable, and more modes quickly became available, such as assist-control (A/C) and then pressure support. (PS). A flow sensor inline allowed clinicians to monitor delivered tidal volumes (VT) and eventually led to volume-targeted ventilation, commonly referred to as volume guarantee (VG). As well, flow triggering became the norm, being much more sensitive than pressure triggering.
Historically, ventilation was adjusted based on the amount of chest excursion. Seeing how much volume was actually being delivered was a revelation. It was soon realized that high VTs were being delivered even at relatively low pressures, and "adequate" chest excursion was a crude estimate, often delivered very high (and damaging) VT. Before VG was introduced, volumes were targeted manually, often at $5-6 \mathrm{ml} / \mathrm{kg}$. While this volume is acceptable in the older infant population, decreasing gestation age calls for decreasing VT since usable lung volume decreases and little volume is required to damage conducting airways. It was not long before the unit where I practice began using a fairly standard 4 $\mathrm{ml} / \mathrm{kg}$ target.

\section{"Twenty-five years after its introduction, SIMV is still used in some units. As I near retirement age, it occurs to me that it is also time for SIMV to be retired as a standard mode.}

Twenty-five years after its introduction, SIMV is still used in some units. As I near retirement age, it occurs to me that it is also time for SIMV to be retired as a standard mode. As the rate increases, the synchronicity of SIMV decreases. Once a rate of 40 is reached, there is little "window" time for the machine to synchronize, and breath stacking may occur. A/C provides more stable VT (when VG is not used), decreases work of breathing, and better facilitates weaning. (1)

PS provides even better synchronization because the delivered breath is terminated based on flow. (1)Thus, the infant is afforded more control of their breathing, and the lung is better protected because it is the infant that decides when they've had enough VT. A caveat when switching to $P S$ from $A / C$ is that mean airway pressure (MAP) is decreased. As a result, an increase in PEEP may be required to maintain optimal lung inflation. (2)

Using the VG adjunct provides the highest level of lung protection; however, this too comes with a caveat: the lung must be adequately recruited. If lung recruitment is only at $50 \%$, then a "protective" VT of $4 \mathrm{ml} / \mathrm{kg}$ is really $8 \mathrm{ml} / \mathrm{kg}$ and is not protective at all. It has taken a long time for clinicians to recognize this and adjust PEEP levels accordingly. Nevertheless, "PEEPophobia" is still a widespread malady and is the antithesis to lung-protective ventilation in any mode.

In the extremely small/premature infant, it stands to reason that VT should also be small. If forced to use CV in this population,

NEONATOLOGY TODAY is interested in publishing manuscripts from Neonatologists, Fellows, NNPs and those involved in caring for neonates on case studies, research results, hospital news, meeting announcements, and other pertinent topics.

Please submit your manuscript to: LomaLindaPublishingCompany@gmail.com 
I prefer to use $3 \mathrm{ml} / \mathrm{kg}$, shorter Ti (when using A/C), and higher rates. $\mathrm{Ti}$ is adjusted using flow graphics to minimize breath holding at end inspiration. This, at least in theory, should reduce gas trapping and volutrauma. Again, adequate functional residual capacity (FRC) must be maintained, and lower Ti and accompanying lower PIP required with lower VT may require higher PEEP. Longer Ti may be used with PS since the baby controls breath termination, and a longer Ti allows the baby to draw a larger breath if desired.

\section{"An important consideration when} using ventilators with flow sensors is the quality of the signal provided to the machine. Contacts on the flow sensor and/or the flow sensor cable can corrode or have poor connections, providing inaccurate measurements (a problem with hot wire anemometer sensors)."

An important consideration when using ventilators with flow sensors is the quality of the signal provided to the machine. Contacts on the flow sensor and/or the flow sensor cable can corrode or have poor connections, providing inaccurate measurements (a problem with hot wire anemometer sensors). Sensors may calibrate successfully but still measure inaccurately. Water accumulation may also interfere with accurate flow measurement regardless of the device. Cables on hotwire anemometers should not be positioned dependently; similarly, pressure lines from a pneumotachometer should also be positioned in an upright orientation. Once again, the quality of the flow graphic is related to the quality of the signal. Be suspicious if a machine is consistently using full PIP to deliver the set VT, which may indicate a poor signal. If pressing the cable into the flow sensor results in lower PIP and a better flow graphic, it indicates either the flow sensor or the cable (or both) should be changed. Any signal dampening will also reduce trigger sensitivity, thus increasing work of breathing and asynchrony.

"Even the most sophisticated ventilators can still be fooled by the accumulation of water in the circuit. Water sloshing back and forth can cause auto-triggering and should be suspected if an infant's respiratory rate is consistently high."

Even the most sophisticated ventilators can still be fooled by the accumulation of water in the circuit. Water sloshing back and forth can cause auto-triggering and should be suspected if an infant's respiratory rate is consistently high.

Perhaps one of the most controversial lung-protective strategies is permissive hypercapnia. While widely used, what constitutes permissive hypercapnia is a matter of debate. $\mathrm{PaCO}_{2}$ of $45-55$ $\mathrm{mmHg}$ is widely cited, but much higher levels are often allowed. Low $\mathrm{CO}_{2}$ is associated with reduced cerebral blood flow, while high $\mathrm{CO}_{2}$ results in cerebral vasodilation and may promote vessel leakage, resulting in brain injury. Hypercapnia also impairs cerebral blood flow regulation. (3)

Just how high or low $\mathrm{PaCO}_{2}$ must be to result in damage depends on several factors. Rapid changes in $\mathrm{PaCO}_{2}$ are inadvisable as it stands to reason reperfusion injury may result similar to that following hyperoxia. Gestational age likely also plays a part with more premature infants being more susceptible to injury, particularly during the critical first 72 hours. For instance, a term or nearterm infant can rapidly drop their $\mathrm{PaCO}_{2}$ during a crying fit with no discernable effect. I have personally ventilated infants with severe compensated respiratory acidosis $\left(\mathrm{PaCO}_{2}>80 \mathrm{mmHg}\right)$ and regularly allow $\mathrm{PaCO}_{2}$ to rise into the $70 \mathrm{~s}$. This practice has not appeared to result in neurological sequelae based on rates of interventricular hemorrhage or periventricular leukomalacia. I believe the key here is a gradual increase in $\mathrm{PaCO}_{2}$ allowing for $\mathrm{pH}$ compensation and avoidance of high or low levels during the first week of life, particularly in the micro-prem. Nevertheless, severe hypercapnia has been linked to white matter injury, and clinicians should proceed with caution until the risk-benefit ratio is better established. There is no question that maintaining "normal" $\mathrm{CO}_{2}$ levels by increasing mechanical ventilation results in further lung damage.
"The current shift towards early extubation and non-invasive support (and avoidance of intubation entirely) is likely to result in improved outcomes, particularly in units where HFV is not routinely used."

The current shift towards early extubation and non-invasive support (and avoidance of intubation entirely) is likely to result in improved outcomes, particularly in units where HFV is not routinely used. As discussed in a previous column, this may not be the case in the sub-25-week gestation strata. (4)

In summary, if using $\mathrm{CV}$ in the premature population, lung damage may be reduced by using low volumes with volume-targeted ventilation, using fully synchronous modes such as $P S$ or $A / C$, optimizing PEEP, avoidance of over-ventilation/hypocapnia, judicious permissive hypercapnia, and extubation at the earliest opportunity. As with any mode of respiratory support, avoidance of high $\mathrm{FiO}_{2}$ is also advisable.

\section{References:}

1. Al Hazzani F, Al Hussein K, Al Alaiyan S, Al Saedi S, Al Faleh $K, A l$ Harbi $F$, et al. Mechanical ventilation in newborn infants: Clinical practice guidelines of the Saudi Neonatology Society. Journal of Clinical Neonatology. 2017;6(2). doi: 10.4103/ jcn.JCN_131_16.

2. Brown $\bar{M} K$, DiBlasi RM. Mechanical ventilation of the premature neonate. Respir Care. 2011;56(9):1298-311; discussion 311-3. Epub 2011/09/29. doi: 10.4187/respcare.01429. PubMed PMID: 21944682.

3. Kaiser JR, Gauss CH, Williams DK. The Effects of Hypercapnia on Cerebral Autoregulation in Ventilated Very Low Birth Weight Infants. Pediatric Research. 2005;58(5):931-5. doi: 10.1203/01.pdr.0000182180.80645.0c.

4. Graham R. Non-invasive Ventilation (NIV): Are we throwing 
some babies out with the bathwater? Neonatology Today. 2019;14(3).

Disclosures: The author receives compensation from Bunnell Inc for teaching and training users of the LifePulse HFJV in Canada. He is not involved in sales or marketing of the device nor does he receive more than per diem compensation. Also, while the author practices within Sunnybrook H.S.C. this paper should not be construed as Sunnybrook policy per se. This article contains elements considered "off label" as well as maneuvers, which may sometimes be very effective but come with inherent risks. As with any therapy, the riskbenefit ratio must be carefully considered before they are initiated.

\section{.NT}

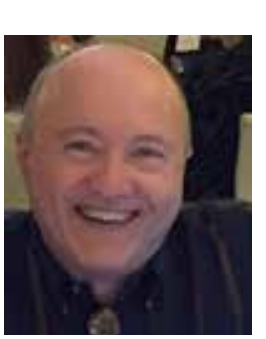

\section{Corresponding Author}

Rob Graham, R.R.T./N.R.C.P.

Advanced Practice Neonatal RRT

Sunnybrook Health Science Centre

43 Wellesley St. East

Toronto, ON

Canada M4Y $1 \mathrm{H1}$

Email: Rob Graham <rcgnrcp57@yahoo.ca>

Telephone: 416-967-8500

\section{Oo National Perinatal Association PERINATAL MENTAL HEALTH}

nationalperinatal.org/position

www.nationalperinatal.org/mental_health

\section{EDUCATE PROVIDERS}

All perinatal health care providers need training and education that will help them support families.

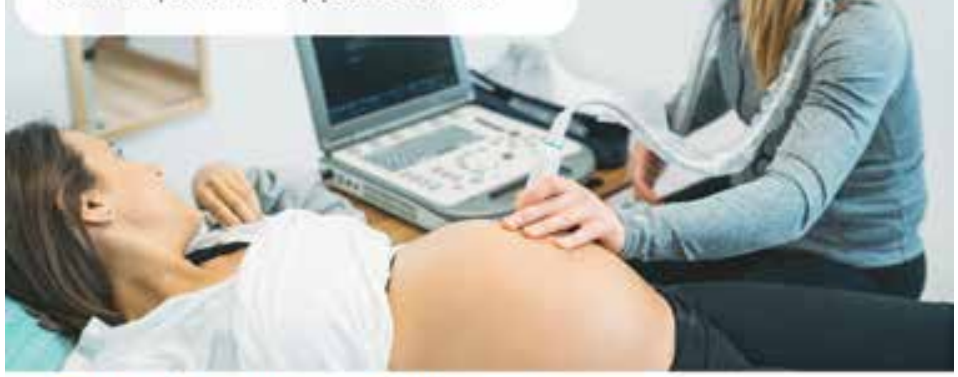

Educate. Advocate. Integrate.

\section{Readers can also follow NEONATOLOGY TO via our Twitter Feed @NEOTODAY}

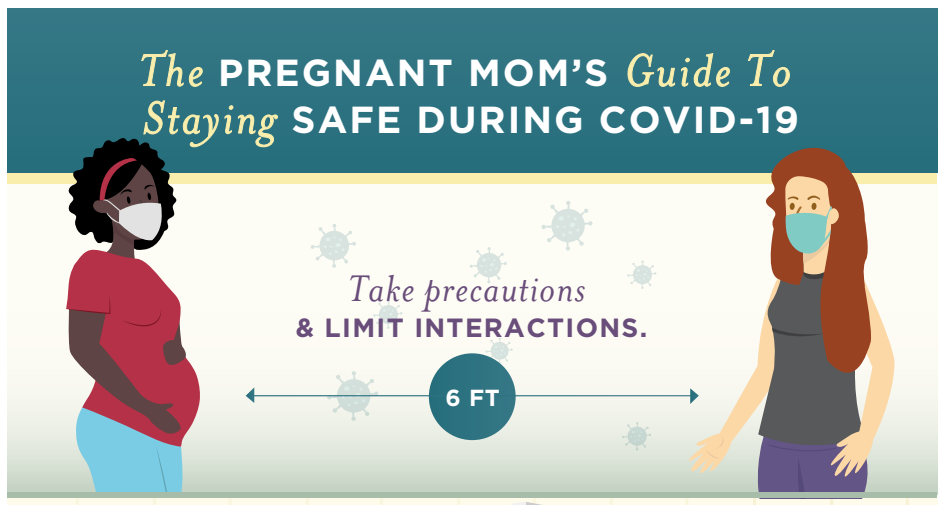

Maintain at least

A 30-DAY SUPPLY

OF YOUR MEDICATIONS.

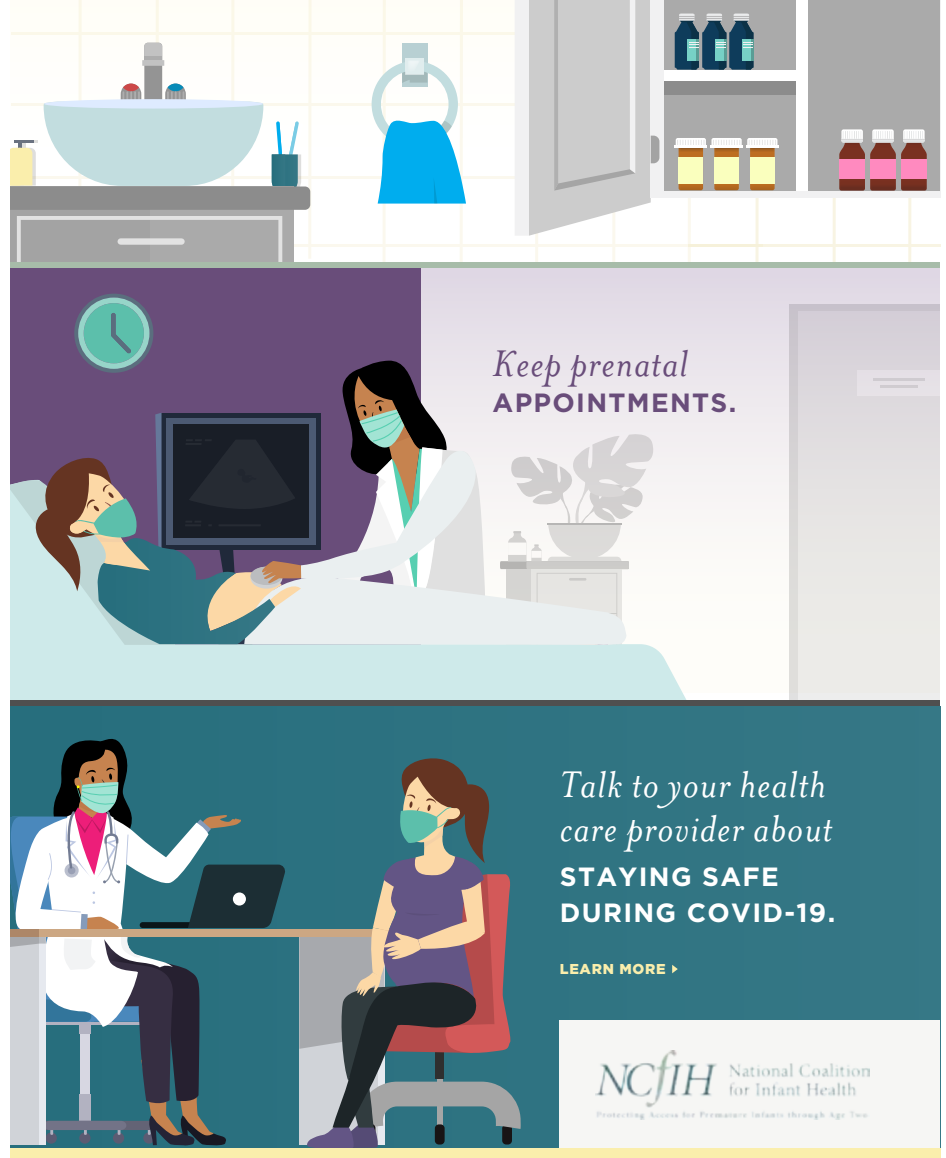

